http://jmscr.igmpublication.org/home/

ISSN (e)-2347-176x ISSN (p) 2455-0450

crossref DOI: https://dx.doi.org/10.18535/jmscr/v9i11.22

\title{
Gigant Morgagni Congenital Hernia Associated with Intestinal Malrotation and Meckel Diverticulum in Child with Down Syndrome- Clinical Case Presentation and Literature Review
}

\author{
Authors \\ Babuci S., 1, 2 Negru I., 1 Eremia V., ${ }^{1,2}$ Malanco S. 1 \\ ${ }^{1}$ IMSP Mother and Child Institute "Natalia Gheorghiu" National Scientific-Practical Center for Pediatric \\ Surgery \\ 2 ."Nicolae Testemitanu" State University of Medicine and Pharmacy Scientific laboratory "Surgical \\ infections in children" (Chisinau, Republic of Moldova)
}

\section{Introduction}

Morgagni congenital hernia is an intrathoracic protrusion of the abdominal contents by a congenital retrosternal diaphragmatic defect, caused by fusion disorders of the diaphragmatic transverse septum and chondrocostal arches (Larrey slot), triangular spaces located anteriorly between the diaphragmatic bundles ${ }^{[3,5,11]}$.

There is some confusion about the name of this diaphragmatic hernia, with some authors using the term "Morgagni hernia" for the right hernia and "Larrey hernia" for the left hernia ${ }^{[22]}$. In the literature this type of congenital diaphragmatic defect can also be found under the name of: Morgagni-Larrey hernias, retro-costo-xiphoid, parasternal, retrochondrosteranal, retrosternal, substernal, etc. ${ }^{[5,22]}$.

Morgagni's hernia is relatively rare, accounting for approximately $3-5 \%$ of all types of congenital diaphragmatic hernia. About $90 \%$ of this type of hernia occurs on the right, $2 \%$ on the left, and in $8 \%$ of cases bilateral forms are found. The herniated sac is present in over $95 \%$ of cases ${ }^{[7,10}$, 25].
The incidence of abnormalities associated with Morgani hernia is about $64 \%$, in $30-40 \%$ of patients with Down syndrome, and in $23-44 \%$ being found congenital heart malformations ${ }^{[4,7]}$. Other malformations associated with this type of diaphragmatic defect are: Cantrell's pentalogy, Noonan syndrome, Pradere Willi syndrome, Turner syndrome, intestinal malrotation, anorectal malformations, etc. ${ }^{[4,9,10]}$.

Usually, these hernias are asymptomatic, being diagnosed incidentally on a radiological examination. Symptomatic forms are characterized by the presence of non-specific gastrointestinal or respiratory symptoms, rarely being found severe respiratory distress, cardiac tamponade, strangulation of the intestine or gastric volvulus ${ }^{[7,13]}$. Although Morgagni's congenital hernia is specific to children, asymptomatic forms have been diagnosed primarily in adults and even in elderly patients ${ }^{[19,26]}$.

The relative rarity of Morgagni hernia with the presence of rough symptoms in a child with Down disease and the association with other malformations of the digestive tract, which may significantly influence the postoperative course, 
led us to describe a clinical case in a young child initially managed as lung tumor.

\section{Clinical Case Presentation}

Patient L., birth in 2018, was consulted at the emergency unit on 06.07.2021 of the IMSP Mother and Child Institute in connection with a persistent dry cough present for several days, accesses becoming more frequent in the last 8
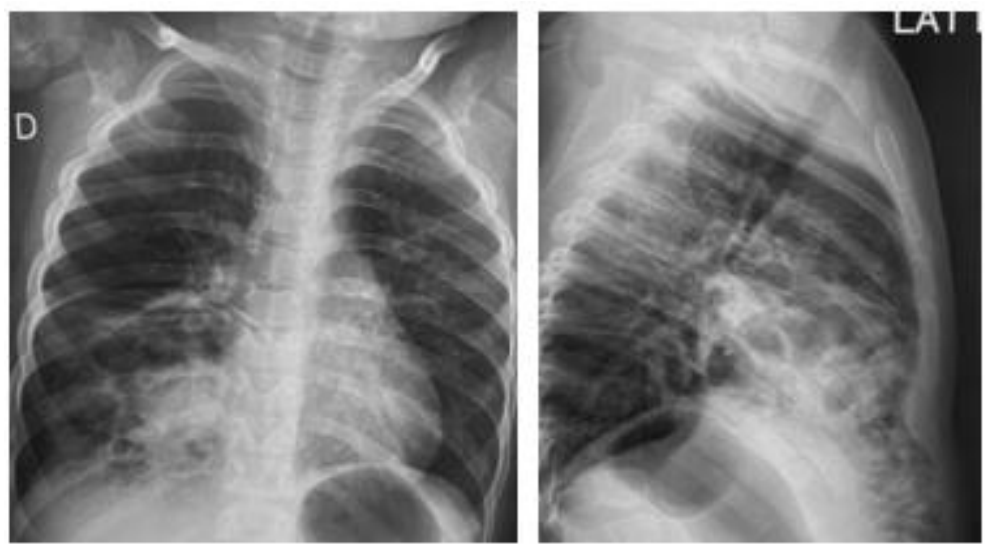

Fig. 1. Patient L., 3 years. Chestradiography in 2 projectionsperformed at thetime of addressing (explanations in the text).

With suspicion of a process of intrathoracic volume or lung abscess, the patient was hospitalized. The anamnestic data allowed us to specify that the child was born at term, being found the Down syndrome, later confirmed by genetic investigations. At the age of 3 months he suffered bilateral bronchopneumonia. Subsequently, the child was under the supervision of neurologists, with a good clinical course.

Objective examination showed characteristic signs of Down syndrome. Laboratory investigations - no obvious deviations. No significant changes were observed in electrocardiography and echocardiography.

Chest radiography with contrast of the gastrointestinal tract (fig. 2) allowed to establish radiological data of anterior diaphragmatic hernia on the right (Morgagni type) with content in the hernial sac of the loops of the small and large intestine, at the L3 level detecting radiopositive foreign body. During the procedure the child vomited with contrast mass and aspirated, due to hours, without other associated symptoms. Suspecting a respiratory tract infection, a chest radiograph was performed showing inhomogeneous opacity, with non-uniform, welldefined areas of transparency, located in the right cardio-diaphragmatic angle, with overlap on the right contour of the heart and contralateral displacement of the mediastinum (fig. 1).

which bronchoscopy was performed with healing of the bronchial tree.

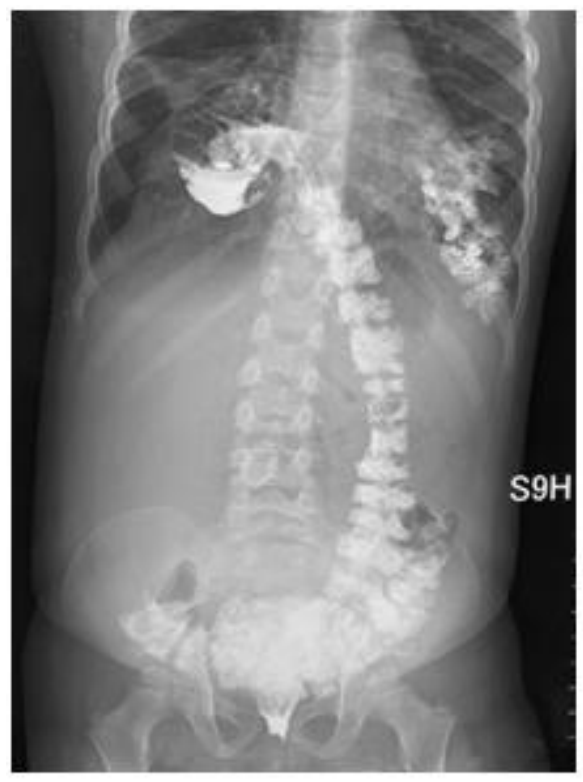

Fig. 2. Patient L., 3 years. Chest radiography with contrast of the intestinal tract performed at 9 hours - the contrast of the colon is determined along the entire trajectory with a portion located superficially on the right intrathoracic. Presence of intrapulmonary contrast agent on the left. 
Fibrogastroduodenoscopy found the displacement of the upper and posterior pylorus. A foreign body (coin) was detected in the D2 duodenum, which was extracted.

For the purpose of differential diagnosis and evaluation of the lung parenchyma, chest CT was performed, which confirmed the diagnosis of right diaphragmatic hernia (Morgagni type) with protrusion of intestinal loops in the thoracic cavity S6, S8, S10 and the suction area of the contrast substance (fig. 3). Infusion lung scintigraphy revealed diffuse changes in bilateral pulmonary blood flow, predominantly in the lower areas of the right lung (fig. 4).

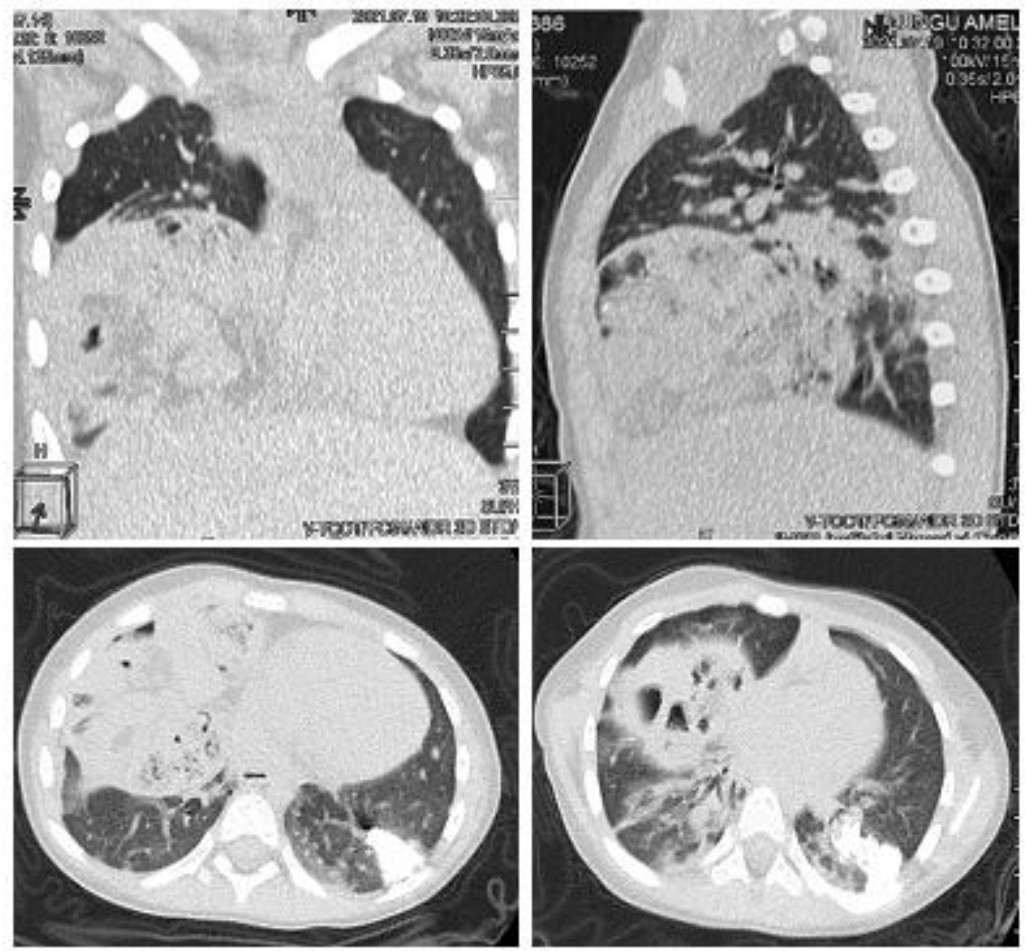

Fig. 3. Patient L., 3 years. CT performed preoperatively (explanations in text)

Anterior

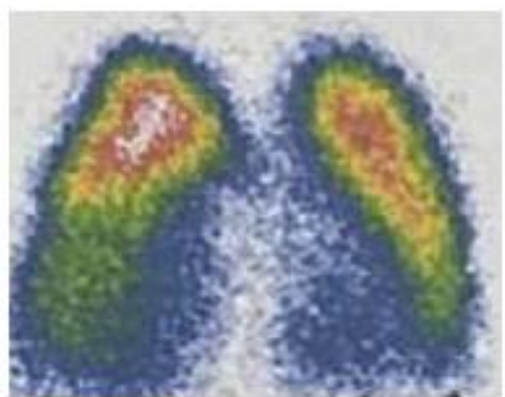

$\mathrm{D}$

$\mathrm{L}$
Posterior

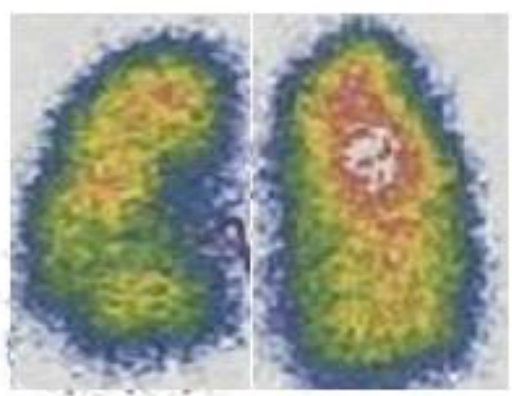

L
D

Fig. 4.. Patient L., 3 years. Pulmonary scintigraphy by preoperative infusion: uneven distribution of the radiopharmaceutical in both lungs; diffuse decrease in pulmonary blood flow in the left lung with multiple areas with significant decreases; decreased pulmonary blood flow in the lower segments of the right lung

After a thorough preoperative preparation, under general anesthesia combined (inhalation + intravenous) with mechanically directed breathing myoplegia, the patient underwent surgery, preferring the abdominal approach - upper median laparotomy. Intraoperatively, a Morgagni hernia was found on the right, as the contents of the hernial sac serving the loops of the small intestine, 
the ileocecal angle with appendix, the omentum that adheres intimately to the sac walls, the ascending colon and partially the transverse colon, established by intestinal malrotation (fig. 5A).
After returning the contents to the abdominal cavity, the rudimentary dimensions Meckel diverticulum was observed (fig. 5B).
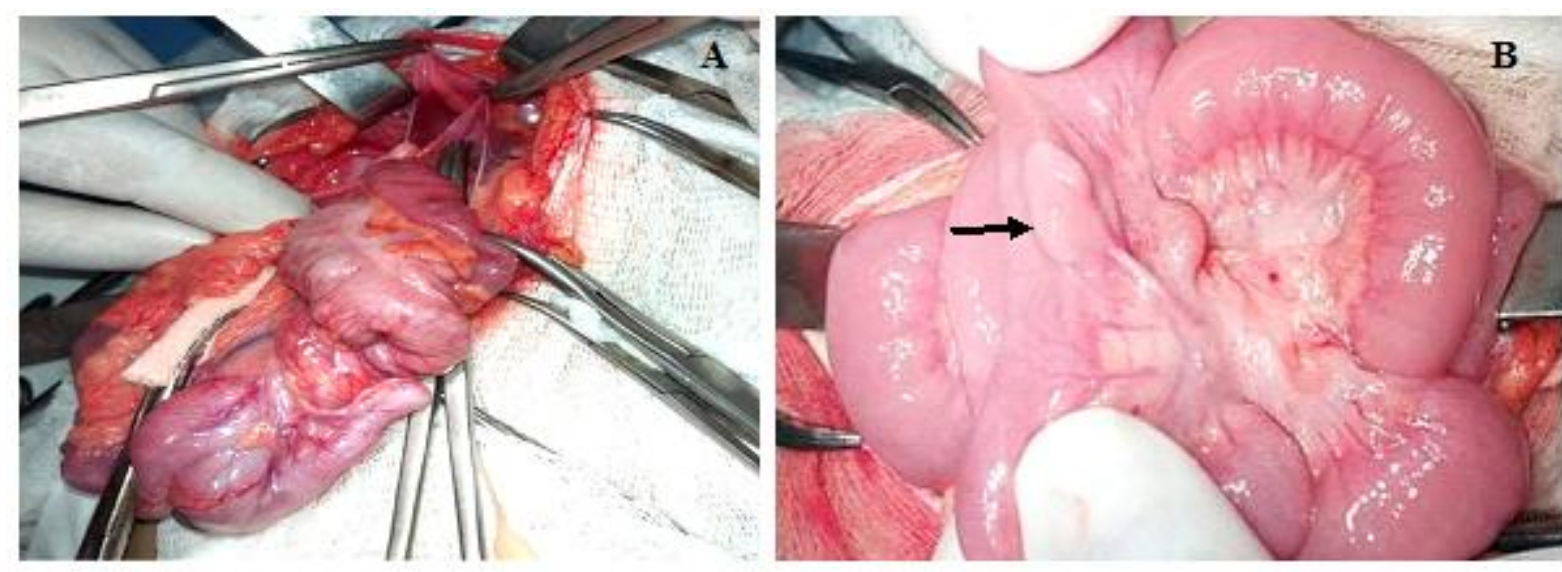

Fig. 5. Patient L., 3 years. Intraoperative aspect: A - thehernial sac andits content returnedtothe abdominal cavity are observed; B - presence of smallMeckeldiverticulum (indicatedbyarrow)

After the repositioning of the intestinal loops in the abdominal cavity, the diaphragmatic defect was plasticized with its own tissues and the surplus of the hernia sac, using non-absorbable interrupted sutures, subsequently the diverticulectomy procedure with enterorafia was performed. Significant enlargement of the left Larrey retroxiphoid fissure was found, which was sutured. The operation was completed with the restoration of the anatomical plane. Histological examination confirmed the presence of the Meckel diverticulum, which had a monomorphic mucosa of the small intestine with lymphoid follicles with reactive changes due to germinal centers and ganglioneuronal immaturity. The postoperative evolution went without complications, the patient being discharged at 10 days in a good condition.

\section{Discussions}

This type of congenital diaphragmatic defect was first described by Giovanni Battista Morgagni in the 18th century. during an autopsy, the year being probably presented by different authors, such as $1761^{[22,23]}, 1769^{[1927]}$ or $1790^{[15]}$. To clarify things, it should be noted that Larrey, who was Napoleon's surgeon, did not describe any hernia, but developed the surgical approach to the pericardial cavity through the anterior retrosternal diaphragmatic defect on the left side ${ }^{[1,22]}$.

Morgagni's foramen represents a retrosternal space as a result of the failure of the fusion of the fibrotendinous portion of the tendon (pars tendinalis), which originates from the costochondral arches, with the fibrotendinous portion of the sternal part (pars sternalis), causing a defect between the sternal and costal origin of the diaphragm. Usually, this space is filled with adipose cellular tissue, being covered superiorly with pleura and inferior peritoneum ${ }^{[21]}$.

More commonly, Morgagni hernia contains the large intestine or omentum (Eva Gudumac et al., 2009), but may contain the small intestine, stomach, spleen, and liver ${ }^{[1,2,27]}$. According to the study conducted by Al-Salem A. and coauthor. (2014) the contents of the hernia sac included the colon in $62.3 \%$ of cases, part of the left lobe of the liver - $24.5 \%$ of cases, the small intestine $20.75 \%$ of cases, the omentum $-9.4 \%$ of cases and the stomach $-7,6$ case, at the same time in $22.6 \%$ of cases the hernia sac being empty ${ }^{[2]}$.

Intestinal malrotations are relatively common in newborns with diaphragmatic hernia (42-80\%), due to abnormal rotation of the middle intestine in the embryological period, ranging from a mobile 
cecum with non-fixation of the right colon. Management of malrotation in these cases being a topic of discussion ${ }^{[8,12]}$. Some studies indicate an association between right Morgagni hernia and intestinal malrotation with malfunction, which can cause devastating consequences ${ }^{[3,8]}$.

Chest radiography is the most commonly used method in the diagnosis of Morgagni hernia. In some cases an ultrasound proves to be quite useful, and some authors use contrasting studies of the upper and lower gastrointestinal tract ${ }^{[11,17]}$. A CT scan has the advantage of visualizing the defect and an evaluation of the size of the hernial sac and its contents ${ }^{[7]}$.

Surgery in this diaphragmatic defect is absolutely necessary, being called into question the need for resection of the hernia sac. However, opinions differ regarding the surgical treatment of asymptomatic forms ${ }^{[2,4,6,20]}$. A controversial point remains the use of the surgical approach ${ }^{[6]}$. The transthoracic approach ofMorgagni hernia provides sufficient exposure, easy repair of the hernia sac, facilitates the release of pericardial adhesions and has an acceptable morbidity ${ }^{[16]}$. The transabdominal approach provides adequate work space, facilitates the reduction of hernia content, proper assessment of protruding organs and detection of associated gastrointestinal malformations, as well as an easier and safer repair procedure for Morgagni hernia ${ }^{[14,24,28]}$.

Several studies indicate that laparoscopic repair of Morgagni hernia in children is associated with a short duration of surgery and hospitalization compared to open surgery ${ }^{[18]}$. Some authors have indicated the feasibility of using robotic surgery in the treatment of large Morgagni hernia ${ }^{[13]}$.

Therefore, although Morgagni's hernia is rare, a high rate of suspicion should be considered in children with Down syndrome, including asymptomatic patients. This case elucidates the benefits of the transabdominal approach in a child with Morgagni hernia associated with intestinal malrotation and Meckel's diverticulum diagnosed incidentally intraoperatively. This surgical approach provides an excellent exposure of the area of operation and allows an adequate diagnosis of any associated abnormalities, which is important to avoid an associated morbidity caused by the development of serious complications.

\section{Bibliography}

1. Abraham V., Myla Y., Verghese S., Chandran B.S. Morgagni-Larrey hernia - a review of 20 cases. Indian J. Surg. 2012. 74(5):391-5.

2. Al-Salem A., Zamakhshary M., Al Mohaidly M., Al-Qahtani A., Abdulla M.R., Naga M.I. Congenital Morgagni hernia: a national multicenter study. J. Pediatr. Surg. 2014. 49:503-7.

3. Al-Salem A.H. Congenital hernia of Morgagni in infants and children. J. Pediatr. Surg. 2007. 42(9):1539-43.

4. Al-Salem A.H. Congenital Morgagni hernia in infants and children: a national review. Ann. Pediatr. Surg. 2017. 13(4):182-7.

5. Arikan S., Dogan M.B., Kocakusak A., Erozi F., Dari S. et al. Morgagni's hernia: analysis of 21 patients with our clinical experience in diagnosis and treatment. Indian J. Surg. 2018. 80(3):239-44.

6. Aydin Y., Altuntas A.B., Ulas A.B., Daharli C., Eroglu A. Morgagni hernia: transabdominal or transthoracic approach? Acta Chir. Belgica. 2014. 114:131-5.

7. Bawazir O.A., Mahomed A., Fayyad A, Bagaryn E., Bawazir A., Mandora R. Laparoscopic-assisted repair of Morgagni hernia in children. Ann. Pediatr. Surg. 2020. 16:11. https://doi.org/10.1186/s43159-02000022-2.

8. Blood A.G., Whaley Z.L., KadenheChiweshe A.V., Spigland N.A. Cae report: 19M old boy with Morgagni hernia associated with intestinal maltotation. J. Pediatr. Surg. Case Rep. 2020. 52:101341. 
9. Cigdem M.K., Onen A., Okur H., Otcu S. Associated malformations in Morgagni hernia. Pediatr. Surg. Int. 2007. 23911):1101-3.

10. Golden J., Barlowa M., Mitchell I. et al. Repair of a bilateral Morgagni hernia in a premature, extremely low birth weight infant. J. Ped. Surg. Case Rep. 2014. 2:145-9.

11. Gudumac E., Babuci S., Bârsan A., Malanco S. Hernia congenitală Morgagni asociată cu viciu cardiac și sindromul Down la copil: caz clinic. Arta Medica. 2019. 1(34):57-9.

12. Heiwegen K., de Blaauw I., van Ling J., Botden S.M.B.I. Malrotation in congenital diaphragmatic hernia: is really a problem? Eur. J. Pediatr. Surg. 2020. 30(5):434-9.

13. Janssens W., Schoneveld M., Allaeys M., De Backer A. Robotic repair pf large Morgagni hernia in an adolescent girl. J. Pediatr. Surg. Case Rep. 2019. 41:51-3.

14. Karamustafaoglu Y.A., Kuzucioglu M., Tarladacalisir T., Yoruk Y. Transabdominal subcostal approach in surgical management of Morgagni hernia. Eur. J. Cardio-thor. Surg. 2011. 39:100911.

15. Kelly K.A.,Basset D.L. An anatomic reappraisal of the hernia of Morgagni. Surgery. 1964. 55:495-9.1̂

16. Kilic D., Nadir A., Doner E., Kavukcu S., Akal M. et al. Transthoracic approach in surgical management of Morgagni hernia. Eur. J. Cardio-thor. Surg. 2001. 20:1016-9.

17. Kim J.M., Couluris M., Schnapf B.M. Late-presenting left-sided Morgagni congenital hernia in a 9-year-old male. ISRN Pulmonol. 2011. Art. ID 409252. 4 pag. doi:10.5402/2011/409252.

18. Lauriti G., Zani-Ruttenstock E., Catania V.D., Antounians L., Chiesa P.L., Pierro A., Zani A. Open versus laparocopic approach for Morgagni hernia in infants and children: a systematic review and meta-analysis. J. Laparoendosc. \& Adv. Surg. Techn. 2018. 888-893. http://doi.org/10.1089/lap.2018.0103.

19. Loong T.P.F.,Kocher H.M. Clinical presentation and operative repair of hernia of Morgagni. Postgrad. Med. J. 2005. 81:41-4. Doi: 10.1136/pgmj.2004.022996.

20. Măndrăşescu D., Aprodu G., Munteanu V. Hernia retrosternală (hernia Morgagni) la copil - consideraţii asupra a 2 cazuri. J. de Chirurgie. (Iaşi). 2009. 5(2):187-91.

21. Nasr A., Fecteau A. Foramen of Morgagni hernia: presentation and treatment. Thorac. Surg. Clin. 2009. 19:463-8.

22. Paris F., Tarazona V., Casilias M., Blasco E., Canto A. et al. Hernia of Morgagni. Thorax. 1973. 28:631-6.

23. Rattan K.N., Singh J., Dalal P. Childhood Morgagni hernia: report of two ncases. J. Pediatr. Neonatol. Indiv. Med. 2017. 6(1):e060114. Doi: 10.7363/060114.

24. Saleh M.E., Mohammed W.S. Morgagni hernia:how to approach! J. Egyptian Soc. Cardio-Thor. Surg. 2017. 25:171-6.

25. Slepov O., Kurinnyi S., Pomomarenco O., Migur M. Congenital retrosternal hernias of Morgagni: manifestation and treatment in children. Afr. J. Paediatr. Surg. 2016. 13:57-62.

26. Vallee Ph.A. Symptomatic Morgagni hernia misdiagnosed as Chilaiditi sybdrome. West J. Emerg. Med. 2011. 12(1):121-3.

27. Wibawanto A.,Habibie Y.A., Arman. Bilateral Morgagni hernia in infant, a rare type in congenital diaphragmatic hernia: a case series. JKS. 2017. 2:93-102.

28. Yilmaz M., Isik B., Coban S., Sogutlu G., Ara C. et al. Transabdominal approach in the surgical management of Morgagni hernia. Surg. Today. 2007. 37:9-13. 